\title{
Surfactant Lung Lavage versus Standard Treatment for Meconium Aspiration Syndrome
}

\author{
TAREK K. ALSAYAD, M.D.; EHAB I. SOROUR, M.D.; MOHAMED MOUSTAFA, M.D. and \\ ASHRAF ABDELKADER, M.D.
}

The Department of Pediatrics, Faculty of Medicine, Al Azhar University

\begin{abstract}
Background: To evaluate diluted surfactant lung lavage as a therapy for severe meconium aspiration syndrome.

Aim of Study: The aim of this study is to evaluate the efficacy and outcome of lung lavage using diluted surfactant compared to standard protocol for treatment of meconium aspiration syndrome.
\end{abstract}

Patients and Methods: This was a prospective interventional study involved 24 patients with severe meconium aspiration syndrome divided into two equal groups one received the standard care in the form of high frequency ventilation and the second group received pulmonary lavage using diluted surfactant in addition to the standard care. Pulmonary lavage was done using of $15 \mathrm{ml} / \mathrm{kg}$ of surfactant diluted to concentration of $5 \mathrm{mg}$ of phospholipids $/ 1 \mathrm{ml}$ of $0.9 \% \mathrm{NaCl}$ divided into four equal aliquots.

Results: On comparing both groups patients managed by pulmonary lavage using diluted surfactant showed significant improvement in $\mathrm{PCO} 2$ and mean airway pressure occurred 6 hours after lavage while improvement in $\mathrm{PO} 2$, oxygenation index and arterial-alveolar oxygen gradient occurred 24 hours after lavage. The duration of mechanical ventilation, oxygen therapy and hospital stay were shorter in the surfactant group. There was no difference between both groups in the incidence of complications, need for ECMO or death.

Conclusion: Surfactant lung lavage is a safe and effective therapy for severe meconium aspiration syndrome.

Key Words: Meconium-Aspiration - Surfactant-Lavage Neonates.

\section{Introduction}

MECONIUM aspiration syndrome (MAS) is a common cause of respiratory failure in full term newborns. MAS constitute more than $50 \%$ of indications of mechanical ventilation in babies born after 39 weeks [1]. Moreover, MAS is the primary diagnosis for a significant proportion of those

Correspondence to: Dr. Tarek K. Alsayad, The Department of Pediatrics, Faculty of Medicine, Al Azhar University newborns requiring extracorporeal membrane oxygenation (ECMO) in the United States $(26 \%)$ and the United Kingdom (51\%). In the developed world, MAS incidence decreased as low as 1 in 2000 live births. In the developing countries, MAS remains problematic [2].

Intrauterine fetal hypoxia leads to relaxation of sphincters and stimulation of colonic movements with passage of meconium into amniotic fluid. Also, hypoxia itself stimulates gasping intrauterine or during the first few breaths after delivery. The end result is aspiration of meconium into airways $[3,4]$.

Pathophysiology of MAS is complex and includes airways obstruction, meconium induced chemical pneumonitis with release of inflammatory mediators, surfactant dysfunction and persistent pulmonary hypertension. These factors lead to hypoxemia and decreased lung compliance. Poor oxygenation is attributed to a combination of ventilation perfusion mismatching, intrapulmonary shunting due to regional atelectasis and extrapulmonary shunting due to persistent pulmonary hypertension [5].

Meconium impairs lung surfactant by different mechanisms: (a) Displaces surfactant from alveolar spaces, (b) Affects surfactant function by a combined action of its cholesterol and bile acids, (c) Has direct toxicity on type II pneumocytes, and (d) Decreases surfactant proteins A and B [6].

Meconium also has a detrimental effect on placental and umbilical tissues, resulting in vasoconstriction, ulceration, and vascular necrosis, potentially compromising fetal oxygenation. It inhibits fetal lung fluid reabsorption at birth through unknown mechanisms, disturbing the ability of the 
lungs to adapt properly to extrauterine life. Further detailed studies to elucidate the changing concepts in pathophysiology of MAS from mechanical obstruction to the role of immuno-inflammatory mechanisms are required for exploring newer strategies in the management of MAS [7]

Initial therapy for meconium aspiration is supportive aiming to clear meconium through suctioning of upper airways immediately after delivery and tracheal toileting in case meconium-stained newborns soon after delivery if the baby is not vigorous $[7,8]$. When needed, neonate is admitted to intensive care unit (NICU) to maintain adequate oxygenation and optimal blood pressure, correct acidosis, and other metabolic disorders. Supplemental oxygen administration in many less severe cases is the only therapy [9].

About one third of those infants require intubation and mechanical ventilation due to worsening respiratory status. The use of mechanical ventilation carries the hazards of increased risk of barotrauma due to the complicated pulmonary pathophysiology involving areas of atelectasis and areas of hyperinflation, in association with ventilation-perfusion mismatch and airway obstruction. High frequency oscillatory ventilation (HFOV) is now an important means of providing respiratory support for infants with severe MAS failing conventional ventilation [10].

All previous lines of treatment are supportive, but they do not hinder the pathogenesis. Removal of meconium using saline bronchoalveolar lavage was tried with reasonably accepted results, but it has drawbacks of increasing the amount of liquid in the lungs, dilute endogenous surfactant, and cause its partial removal together with the lavage fluid. So, when saline lung lavage is used, substitution of surfactant is recommended [11].

Intra-tracheal bolus of undiluted surfactant as a treatment for MAS was first tried in animals with experimentally induced MAS and showed improvement in pulmonary function. Similar results were observed also in newborns with MAS [12].

Several doses of undiluted surfactant may be required to give adequate results and earlier surfactant administration is associated with better results [2]. Rapid changes in pulmonary vascular resistance and subsequent hemodynamic changes associated with large bolus of surfactant can lead to increased risk of intraventricular hemorrhage. So, when using undiluted surfactant bolus it is better to be divided into several small portions and delivered as a slow tracheal infusion to prevent acute hemodynamic changes [13].

Early pulmonary lavage with diluted surfactant solution was first tried in animals with significant improvement in respiratory function while using smaller amount of surfactant and carrying less drawbacks. Application of this method in neonates with MAS showed good results [14]

For the lung lavage, exogenous surfactant is usually diluted to a concentration of $5 \mathrm{mg}$ of phospholipids $/ \mathrm{ml}$, which is sufficiently resistant to inactivation by meconium and plasma proteins $[2,15]$.

\section{Patients and Methods}

This is a prospective interventional study was carried out at United Doctors Hospital, Jeddah, KSA, over the period from January 2014 till March 2015 and included 24 patients divided into two groups each one was 12 patients. Both groups were diagnosed as meconium aspiration syndrome and fulfilled our inclusion criteria. One group (control group) received the standard care in the form of high frequency ventilation and the second group (intervention group) was additionally managed by pulmonary lavage using diluted surfactant. Both groups received the standard respiratory care.

\section{Inclusion criteria:}

Full term newborn requiring mechanical ventilation during the first 6 hours of life due to meconium aspiration syndrome. Indications of mechanical ventilation were fraction of inspired oxygen (FiO2) requirement $>0.4$, arterial partial pressure of oxygen $(\mathrm{PaO} 2)<50 \mathrm{mmHg}$ and arterial partial pressure of carbon dioxide $(\mathrm{PCO} 2)>60 \mathrm{mmHg}$. We included infants with significant respiratory compromise confirmed by two repeated blood gases showing alveolar-arterial oxygen difference of at least $450 \mathrm{~mm} \mathrm{Hg}$.

- Gestation age >_36 week and birth weight > $2.5 \mathrm{~kg}$.

- Evidence of meconium aspiration syndrome.

- Presence of meconium-stained amniotic fluid or staining of meconium in skin, umbilical cord or nails.

- Presence of meconium below vocal cords.

- Non-vigorous babies.

- Chest X-ray suggestive of meconium aspiration.

- Presence of respiratory distress (Downe's score >_4) within 2 hours of birth.

- Need for mechanical ventilation within $6 \mathrm{~h}$ of birth. 


\section{Exclusion criteria:}

- Major congenital malformations.

- Congenital heart disease.

- Hydrops fetalis.

- Air leaks, before Surfactant Lung lavage.

- Pulmonary hemorrhage, before Surfactant Lung lavage.

- Infants in whom transfer to other hospital is likely.

\section{Primary outcome:}

- Change in respiratory indices: Oxygenation index (OI), alveolar-arterial Oxygen gradient (A-a gradient), and mean airway pressure (MAP). These values were measured from before and 1 , $6,24 \mathrm{~h}$ and 48 hours following treatment.

- The duration of mechanical ventilation, oxygen therapy and hospital stay were determined.

\section{Secondary outcome:}

- Complications: Incidence of pulmonary hypertension by Echocardiography and pneumothorax by chest X-ray, intracranial hemorrhage confirmed by cranial ultrasound.

- Incidence of sepsis: Confirmed sepsis defined as sepsis Screen positive + Blood or CSF culture positive for bacteria.

Sepsis screen:

- Total leukocyte count $<5000 / \mathrm{mm}^{3}$.

- Absolute neutrophil count <1500/cu.mm.

- Immature/total neutrophil ratio $>0.2$.

- Micro-ESR >15mm in ${ }^{1 \text { st }}$ hour.

- C Reactive Protein (CRP) > 1 0mg/dl.

\section{Surfactant lung lavage:}

Surfactant lung lavage was performed on the study group of newborns during the first 6 hours of life. The natural surfactant (Survanta; Abbott Laboratories, Abbott Park, IL, USA) was diluted to concentration of $5 \mathrm{mg}$ of phospholipids $/ 1 \mathrm{ml}$ of $0.9 \% \mathrm{NaCl}$. The diluted surfactant was given in a dose of $15 \mathrm{ml}$ of solution per $\mathrm{kg}$ of body weight divided into four equal aliquots. Lavage fluid was instilled through a catheter placed $0.5 \mathrm{~cm}$ beyond the endotracheal tube. This was followed by positive pressure inflations (peak pressure as high as $30 \mathrm{~cm} \mathrm{H} 2 \mathrm{O}$ ) using a suitable self-inflating bag. After each surfactant aliquot had been obtained, standard suction system was used to recover as much of the instilled fluid as possible.

\section{Statistical analysis of data:}

Statistical analysis was carried out using the SPSS computer package version 19.0 (SPSS Inc., Chicago, IL, USA). The collected data were statistically managed as follows:

- For descriptive statistics: The mean $\pm \mathrm{SD}$ were used for quantitative variables while the number and percentage were used for qualitative variables.

- For analytic statistics: Qualitative variables were compared by Fischer's exact test (FET), and quantitative variables were compared by independent samples $t$-test.

- The statistical methods were verified, assuming a significant level of $p<0.05$ and a highly significant level of $p<0.001$.

\section{Results}

This study involved 24 patients with significant respiratory distress due to MAS, 12 patients of them received the standard care including high frequency mechanical ventilation and the other 12 patients were additionally managed by bronchoalveolar lavage using diluted surfactant. There was no significant difference regarding general characteristics of the included newborns as shown in (Table 1). The time of doing bronchoalveolar lavage was $4 \pm 2.9$ (1.1-6.9) hours after delivery. (Tables 2,3 ) show results of respiratory indices for the studied newborns which were measured before intervention and repeated 1, 3, 6, 24 and 48 hours after doing surfactant lavage. The first parameters showed significant difference were PCO2 and MAP which were lower to normal in surfactant group 6 hours after doing surfactant lavage. Also, PO2 was significantly higher in the surfactant group 24 hours after giving surfactant associated in the same time with improvement in OI and A-a gradient. The duration of mechanical ventilation (MV), oxygen therapy and hospital stay were shorter in the surfactant group. There was no difference between two groups in the incidence of complications, need for ECMO or death. 
Table (1): General characteristics of the studied sample.

\begin{tabular}{|c|c|c|c|c|}
\hline & $\begin{array}{c}\text { No surfactant group } \\
\text { No }=12(\%) \\
\text { Mean } \pm \text { SD }\end{array}$ & $\begin{array}{c}\text { Surfactant group } \\
\text { No }=12(\%) \\
\text { Mean } \pm \text { SD }\end{array}$ & $\begin{array}{c}t \text {-test / } \\
\text { FET }\end{array}$ & $\begin{array}{c}p- \\
\text { value }\end{array}$ \\
\hline \multicolumn{5}{|l|}{ Gender: } \\
\hline Male & $7(58.3)$ & $8(66.7)$ & 0.18 & 1.000 \\
\hline Female & $5(41.7)$ & $4(33.3)$ & & \\
\hline Gestational Age (week) & $39.25 \pm 0.62$ & $39.75 \pm 0.62$ & 1.97 & 0.062 \\
\hline \multicolumn{5}{|l|}{ Type of delivery: } \\
\hline NVD & $8(66.7)$ & $7(58.3)$ & 0.18 & 1.000 \\
\hline CS & $4(33.3)$ & $5(41.7)$ & & \\
\hline Birth weight (gm) & $3645.6 \pm 342.7$ & $3782.6 \pm 271.6$ & 1.09 & 0.290 \\
\hline
\end{tabular}

Table (2): PH, PCO2 and PO2 values of the studied newborns.

\begin{tabular}{lllll}
\hline & $\begin{array}{c}\text { No surfactant group } \\
\text { No= } 12(\%) \\
\text { Mean } \pm \text { SD }\end{array}$ & $\begin{array}{c}\text { Surfactant group } \\
\text { No=12 }(\%) \\
\text { Mean } \pm \text { SD }\end{array}$ & $t$-test & $\begin{array}{c}p \text { - } \\
\text { value }\end{array}$ \\
\hline $\mathrm{PH}$ at $0 \mathrm{~h}$ & $7.05 \pm 0.09$ & $7.11 \pm 0.07$ & 1.77 & 0.091 \\
$\mathrm{PH}$ at $3 \mathrm{~h}$ & $7.11 \pm 0.02$ & $7.13 \pm 0.04$ & 1.39 & 0.178 \\
$\mathrm{PH}$ at $6 \mathrm{~h}$ & $7.28 \pm 0.03$ & $7.32 \pm 0.05$ & 1.98 & 0.060 \\
$\mathrm{PH}$ at $24 \mathrm{~h}$ & $7.33 \pm 0.04$ & $7.38 \pm 0.05$ & 2.49 & $* 0.020$ \\
$\mathrm{PH}$ at $48 \mathrm{~h}$ & $7.34 \pm 0.03$ & $7.39 \pm 0.04$ & 2.89 & $* 0.008$ \\
$\mathrm{PaCO} 2$ at $0 \mathrm{~h}$ & $61.5 \pm 3.61$ & $63.5 \pm 2.07$ & 1.67 & 0.110 \\
$\mathrm{PaCO} 2$ at $3 \mathrm{~h}$ & $57.17 \pm 5.86$ & $53.50 \pm 3.80$ & 1.82 & 0.083 \\
$\mathrm{PaCO} 2$ at $6 \mathrm{~h}$ & $52.91 \pm 6.12$ & $47.83 \pm 3.48$ & 2.45 & $* 0.024$ \\
$\mathrm{PaCO} 2$ at $24 \mathrm{~h}$ & $46.0 \pm 3.50$ & $41.42 \pm 2.57$ & 3.58 & $* 0.002$ \\
$\mathrm{PaCO} 2$ at $48 \mathrm{~h}$ & $42.08 \pm 3.23$ & $37.17 \pm 3.88$ & 3.37 & $* 0.003$ \\
$\mathrm{PaO} 2$ at $0 \mathrm{~h}$ & $33.08 \pm 6.33$ & $35.08 \pm 9.49$ & 0.61 & 0.550 \\
$\mathrm{PaO} 2$ at $3 \mathrm{~h}$ & $41.0 \pm 12.14$ & $50.75 \pm 14.58$ & 1.78 & 0.089 \\
$\mathrm{PaO} 2$ at $6 \mathrm{~h}$ & $51.08 \pm 4.69$ & $57.83 \pm 10.53$ & 2.03 & 0.055 \\
$\mathrm{PaO} 2$ at $24 \mathrm{~h}$ & $57.25 \pm 11.04$ & $67.25 \pm 11.37$ & 2.18 & $* 0.040$ \\
$\mathrm{PaO} 2$ at $48 \mathrm{~h}$ & $66.5 \pm 10.81$ & $77.5 \pm 7.44$ & 2.9 & $* 0.008$ \\
\hline
\end{tabular}

${ }^{*} p$-value $<0.05$ is considered significant.

Table (3): MAP, OI and a-A gradient intervals of the studied newborns.

\begin{tabular}{lcccc}
\hline & $\begin{array}{c}\text { No surfactant group } \\
\text { No= } 12(\%) \\
\text { Mean } \pm \text { SD }\end{array}$ & $\begin{array}{c}\text { Surfactant group } \\
\text { No=12 }(\%) \\
\text { Mean } \pm \text { SD }\end{array}$ & $t$-test & $\begin{array}{c}p \text { - } \\
\text { value }\end{array}$ \\
\hline MAP at $0 \mathrm{~h}$ & $18.0 \pm 2.37$ & $17.5 \pm 3.65$ & 0.4 & 0.695 \\
MAP at $1 \mathrm{~h}$ & $16.13 \pm 2.79$ & $15.23 \pm 3.62$ & 0.68 & 0.506 \\
MAP at $6 \mathrm{~h}$ & $15.87 \pm 3.74$ & $12.64 \pm 3.21$ & 2.27 & $* 0.033$ \\
MAP at 24 h & $15.21 \pm 3.32$ & $12.26 \pm 2.68$ & 2.39 & $* 0.026$ \\
MAP at $48 \mathrm{~h}$ & $15.0 \pm 4.56$ & $11.47 \pm 2.77$ & 2.29 & $* 0.032$ \\
OI at 0 h & $32.0 \pm 2.41$ & $34.0 \pm 3.16$ & 1.74 & 0.096 \\
OI at $1 \mathrm{~h}$ & $34.01 \pm 2.62$ & $31.41 \pm 3.65$ & 1.99 & 0.059 \\
OI at 6 h & $29.64 \pm 1.71$ & $26.91 \pm 4.44$ & 1.98 & 0.060 \\
OI at 24 h & $26.17 \pm 5.6$ & $19.46 \pm 4.69$ & 3.18 & $* 0.004$ \\
OI at 48 h & $19.03 \pm 3.65$ & $13.75 \pm 5.13$ & 2.91 & $* 0.008$ \\
a-A gradient at $0 \mathrm{~h}$ & $565.58 \pm 74.03$ & $577.58 \pm 72.77$ & 0.40 & 0.693 \\
a-A gradient at $1 \mathrm{~h}$ & $535.58 \pm 68.52$ & $486.08 \pm 85.52$ & 1.56 & 0.132 \\
a-A gradient at $6 \mathrm{~h}$ & $436.25 \pm 57.08$ & $383.25 \pm 70.14$ & 2.03 & 0.055 \\
a-A gradient at $24 \mathrm{~h}$ & $451.75 \pm 68.46$ & $358.0 \pm 82.51$ & 3.03 & $* 0.006$ \\
a-A gradient at $48 \mathrm{~h}$ & $376.50 \pm 77.81$ & $272.33 \pm 67.9$ & 3.49 & $* 0.002$ \\
\hline
\end{tabular}

${ }^{*} p$-value $<0.05$ is considered significant. 
Table (4): Outcome of the studied newborns.

\begin{tabular}{lllll}
\hline & $\begin{array}{c}\text { No surfactant group } \\
\text { No=12(\%) } \\
\text { Mean } \pm \text { SD }\end{array}$ & $\begin{array}{c}\text { Surfactant group } \\
\text { No=12(\%) } \\
\text { Mean } \pm \text { SD }\end{array}$ & $\begin{array}{c}t \text {-test / } \\
\text { FET }\end{array}$ & $\begin{array}{c}p \text { - } \\
\text { value }\end{array}$ \\
\hline Duration of MV (days) & $6.17 \pm 1.95$ & $4.84 \pm 1.06$ & 2.99 & $* 0.047$ \\
Duration of O2 therapy (days) & $15.67 \pm 3.72$ & $11.92 \pm 2.48$ & 3.28 & $* 0.043$ \\
Duration of hospital stay (days) & $18.67 \pm 5.42$ & $14.61 \pm 3.43$ & 2.19 & $* 0.039$ \\
Pneumothorax & $3(25.0)$ & $1(8.3)$ & 1.20 & 0.590 \\
PPHN & $2(16.7)$ & $1(8.3)$ & 0.38 & 1.000 \\
Sepsis & $1(8.3)$ & $2(16.7)$ & 0.38 & 1.000 \\
Intracranial hemorrhage & $0(0.0)$ & $1(8.3)$ & 1.04 & 1.000 \\
Pulmonary hemorrhage & $1(8.3)$ & $3(25.0)$ & 1.2 & 0.590 \\
Death & $3(25.0)$ & $1(8.3)$ & 1.20 & 0.590 \\
Discharge & $9(75.0)$ & $11(91.6)$ & 0.25 & 1.000 \\
Hemodynamic instability & $3(25.0)$ & $1(8.3)$ & 1.20 & 0.590 \\
Need for ECMO & $3(25.0)$ & $1(8.3)$ & 1.20 & 0.590 \\
\hline
\end{tabular}

MV: Mechanical ventilation. PPHN: Persistent pulmonary hypertension.

${ }^{*} p$-value $<0.05$ is considered significant.

\section{Discussion}

For many years treatment of MAS was mainly supportive in the form endotracheal suction trying to retrieve meconium, and respiratory support waiting for improvement of the ongoing pathology. Such management does not overcome the problem of surfactant deficiency or dysfunction [16]

Treatment of MAS was a subject for continuous research and several methods was tried over the last years. Pulmonary lavage using diluted surfactant showed good results making it a promising therapy [17]

In this study the patients received surfactant bronchoalveolar lavage had shorter duration of mechanical ventilation, shorter duration of oxygen therapy and shorter hospital stay. This was attributed to improved lung mechanics and gas exchange secondary to restoring surfactant function and reduction in the meconium induced lung pathology.

In another multicenter randomized controlled study, there was no significant reduction in duration of respiratory support in infants received surfactant lung lavage and they attributed their results to the late time of performance of lavage (average 14 hours) [2]. The peak inflammatory response that occurs in pulmonary bronchioles occurs between 12 and 24 hours after meconium aspiration. Delayed time of intervention leads to decrease in the chance to stop the ongoing pathology [18].

In this study patients received bronchoalveolar lavage showed significant improvement regarding respiratory indices. The first parameters showed improvement were PCO2 and MAP (6 hours after lavage) this can be explained by significant relief of mechanical obstruction following this procedure. Improvement in $\mathrm{PO}$, a-A gradient and OI occurred later (24 hours after lavage) due to gradual improvement in surfactant function and reduction chemical pneumonitis which may take longer time to improve.

In a study by Hui et al., 2020, there was no significant difference between both gruopsin the oxygen indices or length of hospital stay [19] Actually there may be a wide variation in the degree and time of improvement following surfactant lavage this because the pathogenesis is multifactorial and factors like the onset of intrauterine aspiration and the amount of aspirated meconium cannot be accurately estimated or controlled.

Mortality rate was less in the surfactant lavage group but statistically this difference was not significant. Need for ECMO was less in the surfactant lavage group although it was also statistically not significant, but it may be important in centers where ECMO is not available. Similar results were observed by Dargaville and his colleagues [2] . In another study Hahn and his team failed to find significant effect of lung lavage using diluted surfactant on mortality or need for ECMO while they found a significant effect on the composite outcome of death or use of ECMO [20].

Similarly, another systematic review showed that surfactant lavage produced a statistically significant beneficial effect on the primary outcome of death or need for ECMO in the meta-analysis of the two randomized controlled trials [21]. This was not evident in our study and it may be due to small number of the studied patients. 
There was no significant difference between lavage group and standard treatment groups in complications this may be because these complications can result from the pathophysiology of MAS itself, or secondary to mechanical ventilation taking in consideration the relatively small number of study population. Surfactant therapy itself is not without complications and side effects like hemodynamic instability, pneumothorax and intracranial hemorrhage may occur secondary to acute change in the lung compliance and subsequent hemodynamic effects [22,23]

Aiming to treat surfactant dysfunction in MAS the exogenous surfactant given may be enriched by other substances that delay its inactivation when exposed to meconium. Such substances may be surfactant proteins, phospholipids or polymers. This multimodal approach can result in better outcome [24]. Using exogenous surfactant as a treatment improves respiratory functions but does not have direct anti-inflammatory action. The inflammatory process itself will result in surfactant inactivation $[25,26]$

Kopincova and colleagues showed that combined use of exogenous surfactant and $\mathrm{N}$-acetyl cysteine as anti-oxidative agent shoed better outcome in experimentally induced MAS [27]. Mikolka and colleagues had a trial on animals and stated that combined use of budesonide added to modified porcine surfactant gives better results than use of surfactant alone including better improvement in lung functions and lower plasma levels in inflammatory mediators (IL-1beta, IL-6, IL-8 and TNF) [14].

Compared to giving surfactant bolus, bronchoalveolar lavage using diluted surfactant has advantages of homogenous distribution of surfactant throughout the lungs, using smaller surfactant dose without decreasing the effectiveness of the treatment. Moreover, bronchoalveolar lavage with surfactant enhances the removal of meconium from the lung [28,29].

Two earlier trials used bolus surfactant instead of diluted surfactant bronchoalveolar lavage showed no benefit of bolus surfactant on any significant outcome, including mortality, air leak, or duration of ventilation $[30,31]$

Zhu and his colleagues compared giving surfactant bolus with doing bronchoalveolar lavage with diluted porcine surfactant in full term neonates with MAS and concluded that pulmonary lavage is superior in increasing ventilation and oxygenation efficiency, shortening the duration of mechanical ventilation, reducing the complication rate, and increasing the cure rate [32]

Several limitations of our study were evident. The intervention was not blinded from the clinical team. The small number of subjects may affect the accuracy of results.

In conclusion, lung lavage using diluted surfactant in neonates with MAS has a significant therapeutic effect and improves pulmonary functions in such patients. More clinical trials are needed to establish a clear guidelines for such treatment.

\section{References}

1- PARKER T.A. and KINSELLA J.P.: Respiratory Failure in the Term Newburn. In: Avery's diseases of the newborn (9th edition). By: Gleason CA and Devaskar SU, pp: 647, 2012.

2- DARGAVILLE P.A., COPNELL B., MILLS J.F., et al.: Less MAS Trial Study Group. Randomized controlled trial of lung lavage with dilute surfactant for meconium aspiration syndrome. J. Pediatr., 158 (3): 383-389, 2011.

3- SWARNAM K., SORAISHAM A. and SIVANANDAN S.: Advances in the management of meconium aspiration syndrome", International Journal of Paediatrics, Vol. 2012, Article ID 359571, 7 pages, doi: 10.1155/2012/359571, 2012.

4- YEH T.F.: Core Concepts: "Meconium Aspiration Syndrome: Pathogenesis and Current management", Neo Reviews, Vol. 11, No. 9 September, pp. 503-512, 2010.

5- LINDENSKOV P.H., CASTELLHEIM A., SAUGSTAD O.D. and MOLLNES T.E.: "Meconium aspiration syndrome: Possible pathophysiological mechanisms and future potential therapies", neonatology, Vol. 107, pp. 225-230, 2015.

6- BALLARD R.A., HANSEN T.N. and CORBET A.: Respiratory failure in the term infant. In: Taeusch H.W., Ballard R.A., Gleason C.A., editors. Avery's Diseases of the Newborn. 8 th ed. Philadelphia: Elsevier Inc., 705$722,2005$.

7- HUTTON E.K. and THORPE J.: Consequences of meconium-stained amniotic fluid: What does the evidence tell us? Early Hum Dev., 90 (7): 333-339, 2014.

8- PERLMAN J.M., WYLLIE J. and KATTWINKEL J.: Neonatal resuscitation 2010. International consensus on cardiopulmonary resuscitation and emergency cardiovascular care science with treatment recommendations. Circulation, Vol. 122, No. 16, Supplement 2, pp. 516 538,2010

9- SINGH B.S., CLARK R.H., POWERS R.J. and SPITZER A.R.: "Meconium aspiration syndrome remains a significant problem in the NICU: outcomes and treatment patterns in term neonates admitted for intensive care during a ten-year period", Journal of Perinatology, Vol. 29, No. 7, pp: 497-503, 2009.

10- DARGAVILLE P.A.: Respiratory support in meconium aspiration syndrome: A practical guide. Int. J. Pediatr., 2012: 965159, 2012. 
11- NANGIA S., SUNDER S., BISWAS R. and SAILI A. Endotracheal suction in term non vigorous meconiumstained neonates- a pilot study. Resuscitation, 105: 79 84, 2016.

12- CALKOVSKA A., MOKRA D., DRGOVA A., ZILA I. and JAVORKA K.: "Bronchoalveolar lavage with pulmonary surfactant/dextran mixture improves meconium clearance and lung functions in experimental meconium aspiration syndrome", European Journal of Paediatrics, Vol. 167: pp. 851-857, 2008.

13- HAHN S., CHOI H.J., SOLL R. and DARGAVILLE P.A.: Lung lavage for meconium aspiration syndrome in newborn infants. Cochrane Database Syst. Rev., (4): CD003486, 2013.

14- MIKOLKA P. MOKRA D., KOPINKOVA J., TOMCÍKOVÁ-MIKUSIAKOVÁ L. and CALKOVSKÁ A.: Budesonide added to modified porcine surfactant curosurf may additionally improve the lung functions in meconium aspiration syndrome. Physiol. Res., 62 (Suppl 1): S191S200, 2013

15- SHARMA P., NANGIA S., TIWARI S., GOEL A., SINGLA B. and SAILI A.: Gastric lavage for prevention of feeding problems in neonates with meconium-stained amniotic fluid: A randomised controlled trial. Paediatr. Int. Child Health, 34 (2): 115-119, 2014.

16- CHETTRI S., BHAT B.V. and ADHISIVAM B.: "Current Concepts in the Management of Meconium Aspiration Syndrome", Indian J. Pediatr., Vol. 21. Epub ahead of print, 2016.

17- EL SHAHED A.I., DARGAVILLE P.A., OHLSSON A., et al.: Surfactant for meconium aspiration syndrome in full term/near terminfants. Cochrane Database Syst. Rev., CD002054, 2007.

18- WANG P.W., JENG M.J., WANG L.S., FANG L.J. and SOONG W.J.: "Surfactant lavage decreases systemic interleukin-1b production in meconium aspiration syndrome", Pediatrics International, Vol. 52: pp. 432$437,2010$.

19- HUI, RONGA; JING-JING, PANB,*; YUN-SU, et al: Journal of the Chinese Medical Association: August Volume 83 - Issue 8 - p 761-773 doi: 10.1097/JCMA. $0000000000000357,2020$.

20- HAHN S., CHOI H.J., SOLL R. and DARGAVILLE P.A.: "Lung lavage for meconium aspiration syndrome in newborn infants", Cochrane Database Syst Rev., Vol. 30, No.4: CD003486. doi: 10.1002/14651858.CD003486. pub2, 2013.

21- CHOIA H.J., HAHN S., LEED J., PARK B.J., LEE S.M., KIM H.S. and BAE C.W.: "Surfactant lavage Therapy for meconium aspiration syndrome. A systematic review and meta-analysis", Neonatology, Vol. 101: pp. 183-191, 2012.

22- AZAD K. and MATHEWS J.: "Preventing newborn deaths due to prematurity", Best Pract Res Clin Obstet Gynaecol, Vol. 24. doi: 10.1016/j.bpobgyn.2016.06.001, 2016.

23- LIN H.C., SU B.H., LIN T.W., PENG C.T. and TSAI C.H.: "Risk factors of mortality in meconium aspiration syndrome: review of 314 cases", Acta Paediatr Taiwan, Vol. 45: pp. 30-34, 2004.

24- MOKRA D. and CALKOVSKA A.: "How to overcome surfactant dysfunction in meconium aspiration syndrome?", Respir. Physiol. Neurobiol., Vol. 187, No 1, pp 58-63, 2013.

25- LATZ E. and GOLENBOCK D.T.: "Receptor cross talk in innate immunity", J. Clin. Invest, Vol. 112, pp. 11361137, 2003, 2003.

26- GROMMES J. and SOEHNLEIN O.: "Contribution of neutrophils to acute lung injury”, Mol. Med., Vol. 17: pp. 293-307, 2011.

27- KOPINCOVA J., MOKRA D., MIKOLKA P., KOLOMAZNIK M. and CALKOVSKA A.: "N-acetylcysteine advancement of surfactant therapy in experimental meconium aspiration syndrome: Possible mechanisms", Physiol. Res., Vol. 63, No. 4, pp. 629-642, 2014.

28- MOKRA D and CALKOVSKA A.: "How to overcome surfactant dysfunction in meconium aspiration syndrome?", Respir. Physiol. Neurobiol., Vol. 187, No 1, pp. 58-63, 2013.

29- ROIGES S., CARBONELL-ESTRANY X., FIGUERASALOY J. and RODRIGUEZ MIGUELEZ J.M.: "Efficacy of three treatment schedules in severe meconium aspiration syndrome", Acta. Paediatr., Vol. 93, pp. 6071, 2004.

30- MATURANA A., TORRES-PEREYRA J., SALINAS R., ASTUDILLO P. and MOYA F.R.: "The Chile Surf Group. A randomized trial of natural surfactant for moderate to severe meconium aspiration syndrome", Pediatr. Res., Vol. 57, pp. 1545A, 2005.

31- Chinese Collaborative Study Group for Neonatal Respiratory Diseases: "Treatment of severe meconium aspiration syndrome with porcine surfactant: A multicentre, randomized, controlled trial", Acta. Paediatr., Vol. 94, pp. 896-902, 2005.

32- LIN X.Z., LAI J.D., LAN Z.Y. and LIN Y.Y.: "Clinical effect of endotracheal lavage with porcine pulmonary surfactant in term neonates with severe meconium aspiration syndrome", Zhongguo Dang Dai Er Ke Za Zhi, Vol. 16, No. 7, pp. 709-13, 2014. 


\section{الغسيل الرئوى مخفض التوتر السطحى (سرفاكتانت)

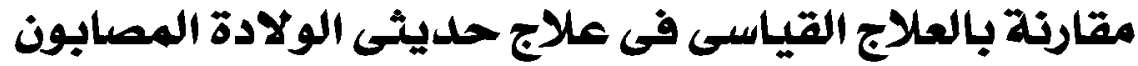 بمتلازمة شفط العقى العى العق}

كان الغرض من هذه الدراسة هو تقييم استخدام مادة سرفاكتانت المخفقة فى الغسيل الرئوى لحالات شفط العقى ومقارنتها بالعلاج

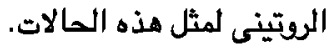

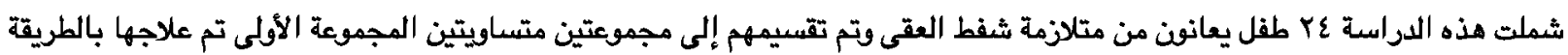

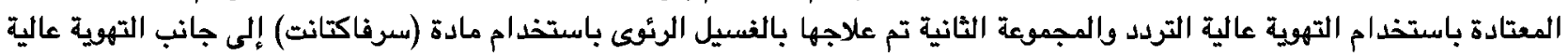

تم استخدام 10 مل من مادة (سرفاكتانت) المخففة مقسمة إلى ع جرعات متساوية وحقنها فى الأنبوبة الرئوية مع استخدام التهوية عالية

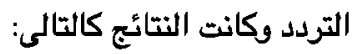

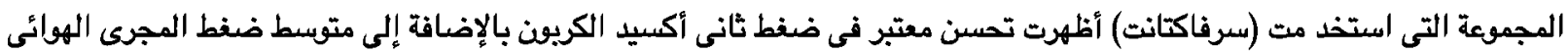

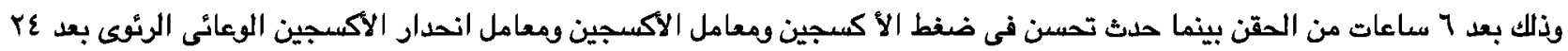
ساعة كما تحسنت لدى هذه المجموعة مدة استخدام جهاز التفس المناعى الاعى ومدة العلاج بالاكسجين ومدة الإقامة بالمستشفى. لم يكن هناك اختلاف يذكر بين المجموعتين فى نسبة حلوث مضاعفات أ وفيات أو استخدام جهاز ECMO. خلاصة البحث: أن الفسيل الرئوى بمادة (سرفاكتانت) المخففة آمن وفعال فى علاج حالات متلازمة شفط العقى. 